\title{
The Chance of a Lifetime: To Learn from the Best
}

\author{
Vera I. Slaveykova*
}

\begin{abstract}
The author describes her experience as a Maitre-assistante at the University of Geneva and the signifi-
\end{abstract} cant influence of Jacques Buffle on her development as an environmental chemist.

Keywords: Department of Inorganic, Analytical and Applied Chemistry · Environmental chemistry . University of Geneva

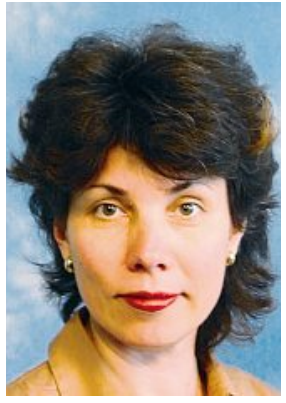

It was by chance that I came to the Department of Inorganic, Analytical and Applied Chemistry of the Section of Chemistry at the University of Geneva. At the time I have been working for a consultancy company. A friendly chat with Kevin Wilkinson during an outing of the group of Analytical and Biophysical Chemistry of the Environment (known as CABE), brought me few months later to my Alma mater. For some of my friends it was difficult to understand why I was leaving a permanent job for another post doc. However, it turned out that this 'return' to academia changed my professional life. Looking for new horizons and searching for new challenges, I was given the opportunity to plunge deeper into the fascinating world of the molecular functioning of environmental systems. The first thing I learned from Jacques Buffle (Fig. 1) was that environmental systems and their functioning are comparable with those of living organisms: both are complex and dynamic, and the understanding of their 'metabolic' state, stress or 'illness' require a number of physical, chemical

${ }^{*}$ Correspondence: Prof. V. I. Slaveykova Environmental Biophysical Chemistry Swiss Federal Institute of Technology Lausanne (EPFL) GR-SLV-IIE-ENAC

Station 2

$\mathrm{CH}-1015$ Lausanne

Tel.: + 41216936331

Fax: + 41216938070

E-mail: vera.slaveykova@epfl.ch and biological processes to be taken into account.

Having arrived at the University of Geneva with a $\mathrm{PhD}$ and experience in the area of analytical chemistry, my new research 'adventure' began with a measurement of lead speciation dynamics with a permeation liquid membrane (PLM). PLM is one of the modern analytical devices developed in Jacques Buffle's group that mimics the processes at the medium/organisms interface. In situ sampling and pre-concentration capabilities make this device very prominent to evaluate and predict biological availability of toxic metals. ${ }^{[1,2]}$

A few months later I had my initiation in culturing and performing different assays with living microalgae. Extremely laborious but grateful work! We were among the first to provide experimental evidence pointing out some overlooked considerations used to link trace metal speciation in natural waters to their availability and potential toxicity to phytoplankton. ${ }^{[3,4]}$ The in-depth study of those 'biotic blocks' of the aquatic systems became possible thanks to the encouragement and continuous support of K. Wilkinson, closely involved in the project. I was so fascinated by those microscopic green chaps that they continue to be among the favourite microorganisms I work with to this day. Linking the speciation of toxic metals to their availability to aquatic microorganisms became one of the pillars of my later research as a Professor fellow of Swiss National Science Foundation at the Swiss Federal Institute of Technology of Lausanne (EPFL).

Studying the particular role of the environmental colloids - 'the essential building blocks of the abiotic medium' - on the metal-microorganism interactions was a further important step in my research development, which obliged me to reconcile my 'pure analytical chemistry' vision with the high polydisperse, polyfunctional and polyelectrolyte features of these entities (Fig. 2). One of the important issues we were able to tackle further was to show the necessity to reconsider some current dogmas about the role of the colloidal organic matter in the trace metal-microorganism interactions. ${ }^{[5,6]}$ This experience convinced me of the importance to deal with distributions, rather than single values of environmental characteristics if I would like to gain deeper insight into the key environmental processes. Next at EPFL I have focussed on the development of the hyphenated flow field-flow fractionation-multi-detection platform enabling the determination of the size distribution of different environmental constituents and associated contaminants. Thus my group became the first one in Switzerland to use such unique hyphenated analytical platform in the environmental context.

I will remember the years spent in Geneva University for the intense, yet rewarding and dynamic work in a friendly, attentive and professionally demanding

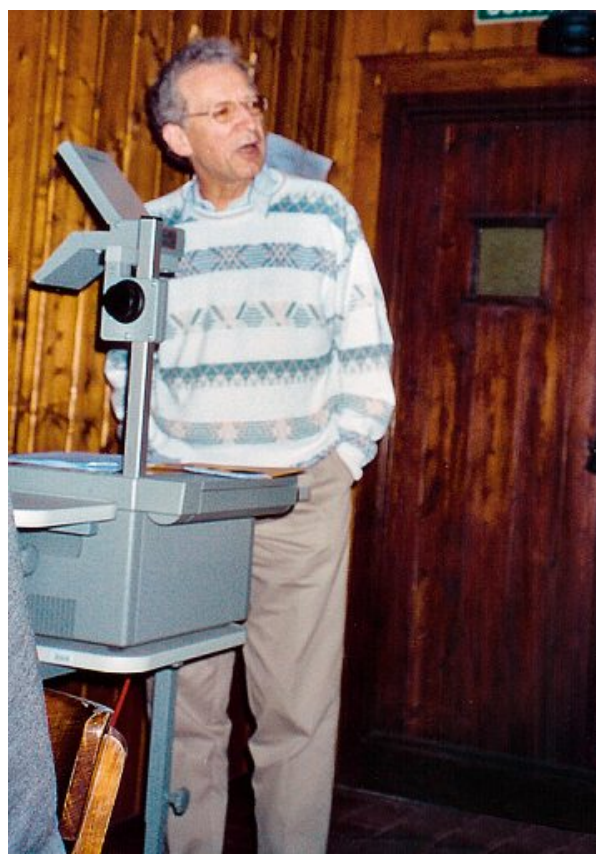

Fig. 1. Jacques Buffle at a group seminar in September 2001 


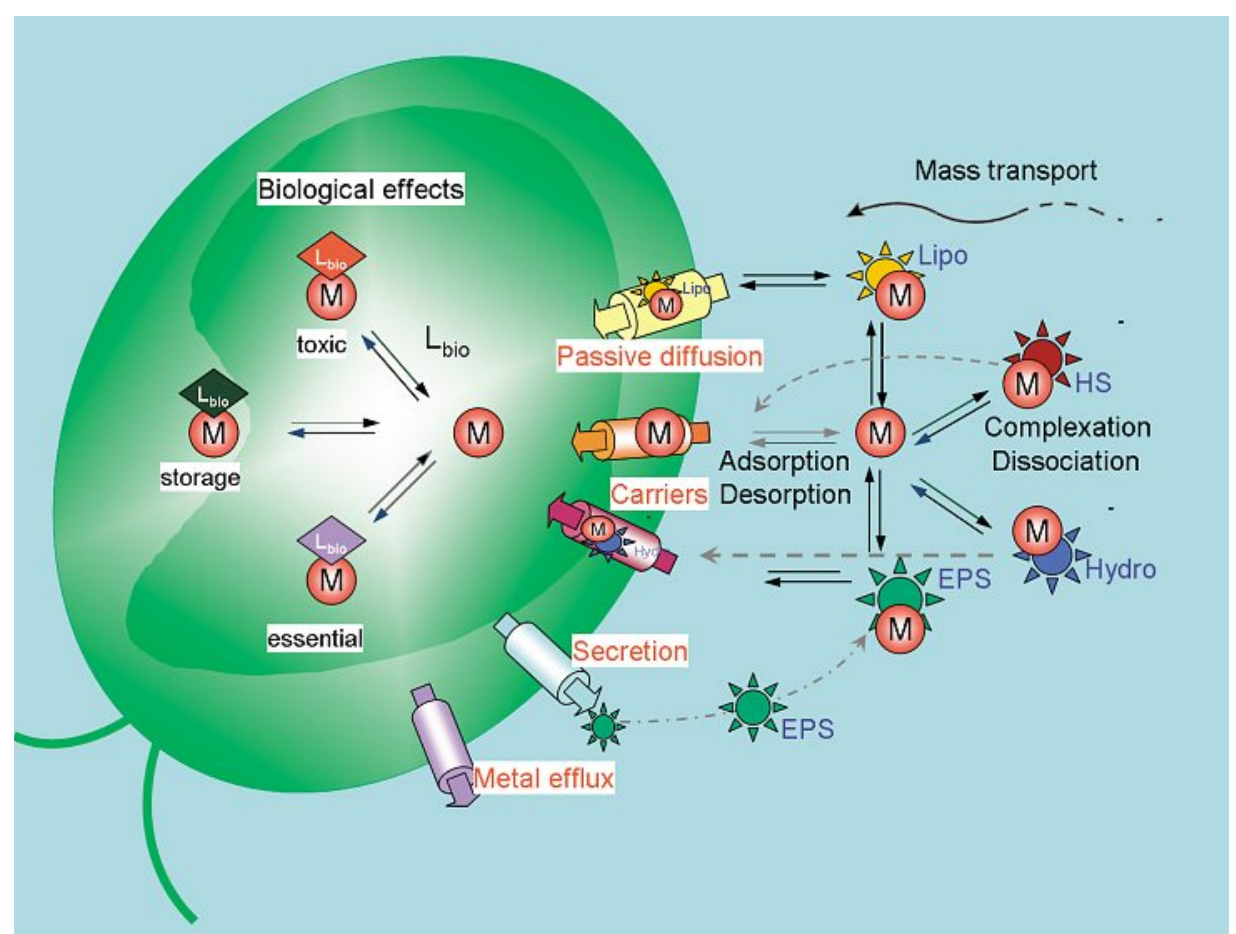

Fig. 2. Bioavailability concept illustrating the interactions between 'biotic and abiotic building blocks' of the aquatic systems. M represents a metal ion, M HS and M EPS are complexes with either humic substances or extracellular polymeric substances; $\mathrm{ML}_{H}, \mathrm{ML}_{\text {lipo }}$ represent complexes with simple hydrophilic and lipophilic ligands; and $\mathrm{ML}_{\text {bio }}$ are the metal complexes with different intracellular ligands.

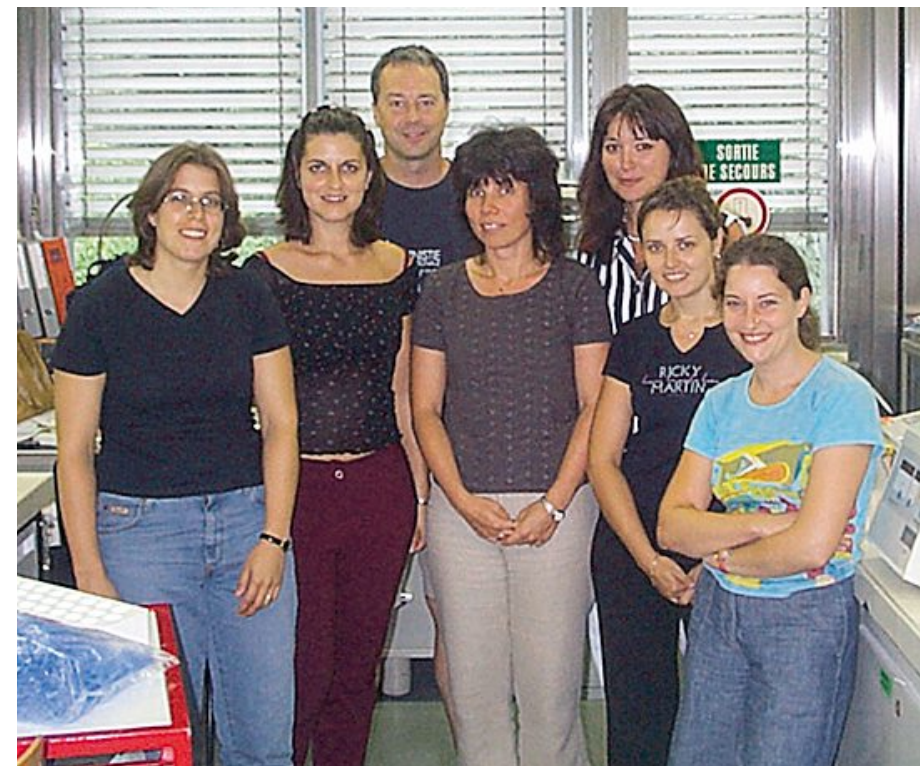

Fig. 3. The girls from 'lab 280' and Kevin Wilkinson, in 2002. From left to right: Christel Hassler, Cristina Lamelas, Vera Slaveykova, Heliana Kola, Dana Simon and Isabelle Worms. team, converted me from an analytical chemist used to apply a rather disciplinary approach to an environmental chemist seeking for multi- and cross-disciplinary ways in addressing scientific questions. Those years gave me a taste to explore the unknown and prepared me to be successful in the ongoing research combining chemical, biological and molecular methods to address two emerging issues at the forefront of the contaminants research: i) assessment of the biogeochemistry and impact to aquatic biota of engineered nanoparticles, and ii) the alteration of the biogeochemical cycles under increased anthropogenic pressure and global and climate change.

Finally, I would like to give tribute and express my heartfelt thanks to those two exceptional persons who influenced my scientific thinking and development, and whom I am proud to consider my mentors: J. Buffle and K. Wilkinson. They encouraged me to do not only better, but always the best. It's a huge luxury to get a chance to work with and learn from the best!

Received: September 29, 2009

[1] V. I. Slaveykova, N. Parthasarathy, J. Buffle, K. J. Wilkinson, Sci. Tot. Environ. 2004, 328, 55.

[2] V. I. Slaveykova, I. B. Karadjova, M. Karadjov, D. L. Tsalev, Environ. Sci. Technol. 2009, 43, 1798.

[3] V. I. Slaveykova, K. J. Wilkinson, Environ Chem. 2005, 2, 9.

[4] C. S. Hassler, V. I. Slaveykova, K. J. Wilkinson, Environ. Toxicol. Chem. 2004, 23, 283.

[5] C. Lamelas, V. I. Slaveykova, Environ. Sci. Technol. 2007, 41, 4172.

[6] C. Lamelas, J. P. Pinheiro, V. I. Slaveykova, Environ. Sci. Technol. 2009, 43, 730. environment, for the motivation and high standards, for the achievements and results, so important for researchers. It has been wonderful to benefit from the friendship, enthusiasm and support of my colleagues and in particular the 'girls from lab 280' (Fig. 3). I feel I have learned so much by explaining things to them and by having them explain things to me. Very enriching, but also very stressful was the period when, as Maître-assistante, I had to introduce J. Buffle's part of the Analytical Chemistry course. The biggest challenge for me was to present the voltammetry topic in a pedagogical way appropriate for students in chemistry and biochemistry. The topic followed very closely one of the chapters in his book on 'Complexation Reactions in the Aquatic Systems: An Analytical Approach'. This is by far one of the landmark books in the area of aquatic chemistry; however it is written for specialized audience and needs serious adaptation for third-year students.

Five years spent at the University of Geneva, as a part of the amazing CABE 